\title{
Hernia vesical inguinoescrotal detectada en rastreo gammagráfico
}

J. Cortés Hernández, J. Extramiana Cameno, J.I. Alonso Colmenares, S. Álvarez Ruiz, $\mathrm{M}^{\mathrm{a}}$ P. Alcorta Armentia

Servicios de Medicina Nuclear y Urología. Hospital Santiago Apóstol. Vitoria.

Actas Urol Esp 29 (3): 338

$\mathrm{V}$

arón de 73 años diagnosticado de adenocarcinoma de próstata (grado 4 de Gleason) clínicamente T1cNOMO, al que se le realiza un rastreo óseo gammagráfico $\left(\mathrm{Tc}^{99 \mathrm{~m}}\right.$-hidroximetilendifosfonato $25 \mathrm{mCi} / 925 \mathrm{MBq})$. Como antecedente personal destacable es portador de una prótesis coxofemoral derecha. El rastreo isotópico muestra una gran acumulación patológica de orina radiomarcada en hemiescroto derecho, no existiendo alteraciones destacables a nivel óseo. La exploración física pone de manifiesto la existen- cia de una hernia inguino-escrotal derecha de gran tamaño. Ante la sospecha de una herniación inguinal de la mayor parte de la vejiga se realiza una cistografia miccional que confirma el diagnóstico.

Dr. J. Cortés Hernández

Servicio de Medicina Nuclear

Hospital Santiago Aposto

Olaguibel, 29

01004 Vitoria (Álava)

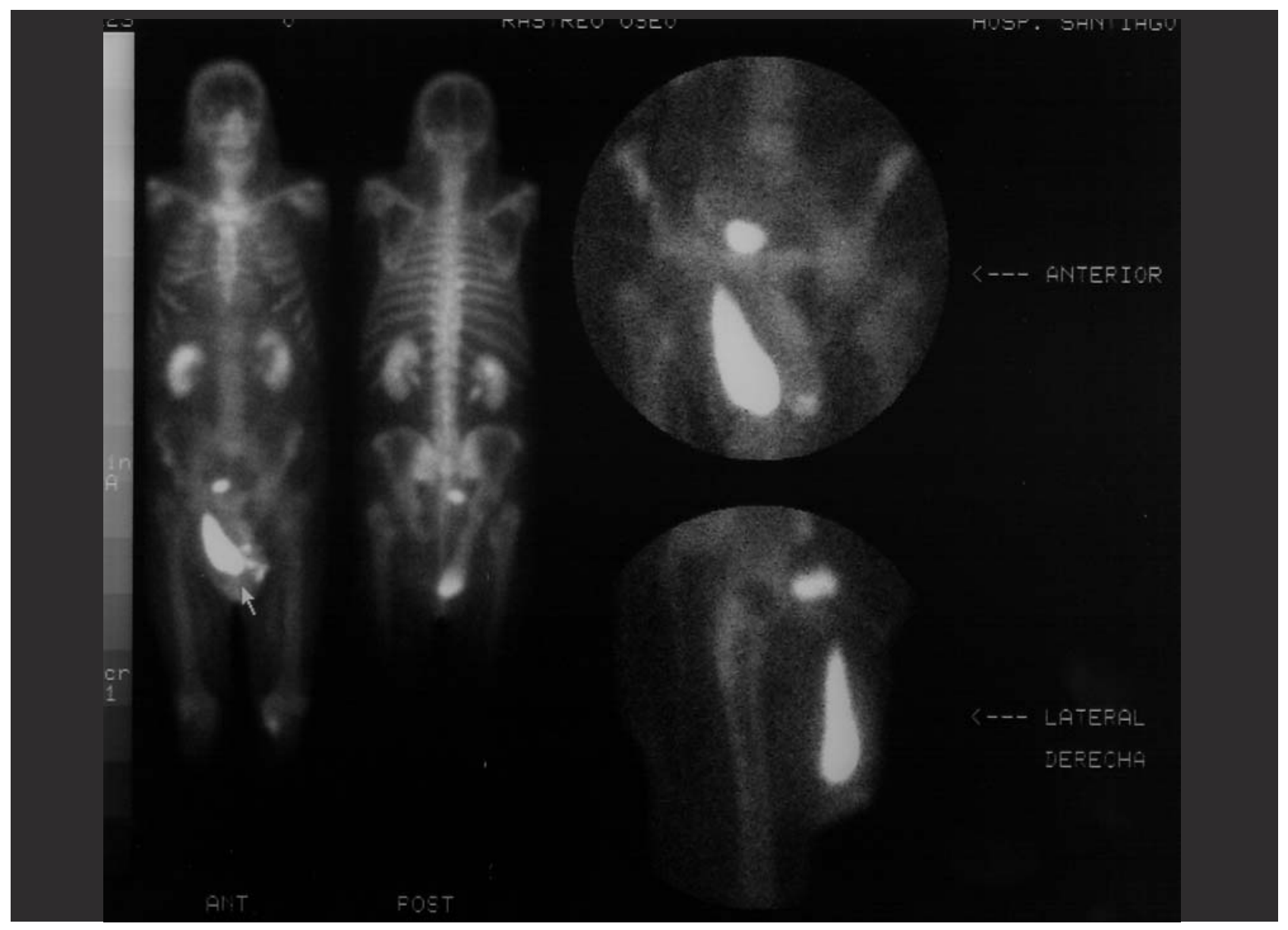

